Article

\title{
Brownfield Redevelopment Evaluation Based on Fuzzy Real Options
}

\author{
Hongjun Dai ${ }^{1,2, *}$, Tao Sun ${ }^{1}$ and Wen Guo ${ }^{1}$ \\ 1 College of Economic and Management, Nanjing University of Aeronautics and Astronautics, \\ Nanjing 211106, China; suntao@nuaa.edu.cn (T.S.); xsyjgw@nuaa.edu.cn (W.G.) \\ 2 College of Economic and Management, Huainan Normal University, Huainan 232000, China \\ * Correspondence: dhj@hnnu.edu.cn; Tel./Fax: +86-554-686-2873 \\ Academic Editors: Seunghwan Myeong and Malin Song \\ Received: 31 October 2015; Accepted: 2 February 2016; Published: 16 February 2016
}

\begin{abstract}
There are a great amount of brownfield in Chinese mining cities. In order to promote mining cities sustainable development, it is necessary to redevelop brownfield. There is a great deal of uncertainty in the process of brownfield redevelopment owing to the influences of pollution. Normal fuzzy numbers were used to describe the fuzziness of the expected DCF (discounted cash flow) value of brownfield redevelopment projects. In view of experts' preferences, the weight of fuzzed estimation intervals of the expected DCF value was determined by means of the lattice closeness degree to find the volatility of the expected DCF value. Combining the results with the B-S (Black-Scholes) real option model, we built a fuzzy real option model which could be applied to the brownfield redevelopment projects. The empirical results showed that the valuation results of the fuzzy real option model, considering the experts' risk preferences, were relatively objective and accurate.
\end{abstract}

Keywords: mining city; sustainable development; brownfield redevelopment; fuzzy real option; normal fuzzy number

\section{Introduction}

In the last thirty years, China has achieved rapid economic growth. China's high-speed economic growth is largely dependent on massive energy consumption [1]. Excessive energy consumption causes serious environmental pollution in China. Environmental control has become a priority of government work. Some scholars have begun to study China's pollution problems from different angles, such as environmental performance evaluation and environmental policy [2,3]. This paper tries to study this from the angle of environmental project assessment.

Brownfield, the opposite word of "greenfield", generally refers to contaminated lands. Those wastelands not only occupy precious land resources, but also ruin the surrounding environment. Therefore, wasteland redevelopment can ease the land shortage crisis, create conditions for city transformation, and can also improve the ecological environment, ensuring inhabitants' physical and psychological health, and improve the quality of the city, which ensures the successful implementation of a sustainable development strategy, as well.

The concept of "brownfield" was coined in Western developed countries. Kivel (1993) [4], Niall (2001) [5], and Rosalind (2004) [6] give multiple definitions from different perspectives. Comprehensive Environmental Response, Compensation, and Liability Act, (also called CERCLA) defines "brownfield" as lands which are previously used for industrial purposes or some commercial uses and may be contaminated by low concentrations of hazardous waste or pollution [7]. Those contaminated lands, after remediation, still have considerable development value $[8,9]$. Therefore, Western developed 
countries attach great importance to the redevelopment of brownfield. The redevelopment of brownfield was mainly affected by two factors, namely, property rights and finance disputes related to the brownfield, and pollution treatment [10]. In addition, it is also affected by other factors, such as policies and funding $[11,12]$. There are a lot of achievements regarding value evaluation on brownfield redevelopment in Western countries. Among the commonly-used valuation methods are the market comparison method, the income capitalization approach, the cost approach method, and the hedonic pricing method. In 1967, Ridker and his coworkers, using the hedonic pricing method, conducted a quantitative analysis on influences of environment quality on the value of the real estate [13]. Rosen (1974) put forward a general method framework for the quantitative analysis [14]. Anish adopted a method combining the hedonic pricing method with GIS when evaluating the value of contaminated real estate in 2007 [15]. The market comparison approach was first applied to evaluate the contaminated land by Campanella in 1984 [16]. Based on land transaction data in southern California, Jackson made a contrastive analysis on brownfields and uncontaminated lands to get the value loss of pollution in 2001 [17]. Wilson studied the cost of brownfield pollution clean-up by means of the probability theory method in 1999 [18]. Mundy drew the conclusion that value loss of land pollution were more than the pollution clean-up cost [19]. Patchin did similar research in 1996 [20]. Bell held the idea that the cost of brownfield pollution clean-up was usually more than what was expected [21]. Richards believed that the influences of pollution on the value of brownfield should also include potential cost of the brownfield which would affect the cash flow in the future, and the negative influences of the stigma effect [22]. Syms came up with a valuation method applicable to the remediation and redevelopment of industrial estate [23]. In further studies, some foreign scholars evaluated the value of brownfield redevelopment using real option approach. Qian Wang and Keith W. Hipel thought there was a great deal of uncertainty and risk for the redevelopment of brownfield [24]. The real option method took the flexibility of the project into account, so it was much better than such traditional methods as the DCF (discounted cash flow) method, and can evaluate the value of brownfield redevelopment projects more accurately. Moreover, combining fuzzy mathematics with real option models, we set up a fuzzy real optional model for evaluating the brownfield redevelopment project. Qian Wang, Hipel [25], Qian Wang, and D. Marc Kilgour improved fuzzy real optional models from different perspectives [26].

In China, the public have not recognized the seriousness of the brownfield problem, and there are few practical and academic research results on brownfield redevelopment. At present, published literature about the valuation of brownfield redevelopment are as follows. Yi Dong et al. summarized the previous research results, discussed and defined key concepts, and emphatically investigated amendments for the traditional valuation methods [27]. Zhang Lin made a contrastive analysis on four popular valuation methods abroad, discussed some representative brownfield redevelopment cases, and then put forward a list of inspiration points for Chinese brownfield redevelopment from four aspects [28]. Yao Shangli described the expected DCF value of the real option model by means of triangular fuzzy numbers, conducted empirical research on a brownfield redevelopment case, and contrasted results with those gotten from the traditional DCF method. The empirical results show that the fuzzy real option method has superiority over other methods for those uncertain investment projects like brownfield redevelopment [29].

To sum up, the brownfield redevelopment project, influenced by pollution factors, is more complicated than general land consolidation projects. At present, the public pay much attention to environmental factors, resulting in high risk and uncertainty for brownfield redevelopment. The brownfield redevelopment can improve the ecological environment and ensure inhabitants' physical and psychological health. There are not only economic benefits, but also social benefits in brownfield redevelopment. This article mainly improves the evaluation methods of economic benefits. Thus, we do not take into account the social benefits of the brownfield redevelopment project in this paper.

The traditional DCF method can generally reflect the static value of the project investment, but cannot reflect the growth opportunity of enterprise investment. Thus, it is likely to lead to underestimate the value of brownfield redevelopment project. There is a two-dimensional (immediately 
investment and give up the investment) choice in the DCF method. The real option approach considers the impact of investment uncertainty. Thus, it is three-dimensional (immediately investment, postpone investment and give up the investment), and it considers the impact of managerial flexibility on project value. Fuzzy decision theory is not based on data (information), but in a data (information) range. Thus, we apply a fuzzy real option model on redevelopment projects.

\section{Application Analysis of Fuzzy Real Option on Redevelopment Projects}

\subsection{Real Option}

The real option theory derives from financial option theories. Option refers to a right of choice, which means the person holding the option can, but is not obliged to, buy assets from the seller according to the predetermined price and amount. Of course, this kind of right comes with a price. As early as 1973, American scholars Black and Scholes set up an option pricing model called Black-Scholes (B-S option model for abbreviation), which was suitable for the call option without dividend-paying stocks. The B-S option model has been honored as the cornerstone of modern finance option pricing theories [30]. It can be read from the B-S option model that prices of underlying stocks, exercise prices, expiration date, return rate and volatility of the underlying stocks, and risk-free interest are the main factors influencing the option price. In 1977, American scholar Stewart Myers [31] proposed a real option theory, in which a project investment opportunity was taken as another kind of option and included in the total value of the project; this kind of option was evaluated in accordance with pricing methods for financial options. Generally speaking, according to specific situations of each investment project, real options can be divided into many groups, such as an option to defer, option to contract, option to expand, option to growth, option to switch, and option to abandon.

\subsection{Fuzzy Real Option}

Although the real option approach takes into account the value of investment opportunities, it also has a disadvantage. The parameters in the model, such as the present value of future cash flows, are assumed to be a fixed value. In fact, it is difficult to make accurate estimates of these parameters. We can only estimate a range of these parameters. Fuzzy numbers can be expressed in a range. The emergence of the fuzzy theory provides a new train of thought for solving real option pricing problems. Therefore, some scholars apply fuzzy mathematics theories to the process of real option pricing. Carlsson and Fuller are forerunners who improved the B-S pricing model by means of fuzzy mathematics theory [32]. In 2003, Carlsson and Fuller set up a real option pricing model for the fuzzy environment. Most of later scholars, along this way of thinking, improved fuzzy real option pricing models and their applications [33-35].

\subsection{Real Option Characteristics of Brownfield Redevelopment Projects}

\subsubsection{Uncertainty}

Brownfield redevelopment is, typically, complex system engineering. It involves environmental systems, social systems, and their subsystems. There is a nonlinear relationship between them. Thus, there are many problems in it, such as uncertainty of development costs, limitations of knowledge and technology, as well as potentially high debt.

\subsubsection{Irreversibility}

Brownfield redevelopment are capital-intensive projects. According to international experience, large sums of money need to be invested in it. At least some of the money is not reversible. This part of the investment are called sunk costs. Land leasing and soil remediation costs are not reversible when the investor wants to change the development strategy. 


\subsubsection{Flexibility}

The flexibility mainly refers to the flexibility of management. The manager can adjust the investment plan of the project according to the investment environment. For example, the manager can delay, reduce, or even abandon the project, to reduce the loss when the external environment is not conducive to investors.

The real option method is more suitable for the evaluation of the brownfield redevelopment project compared with the traditional DCF method. To sum up, the real option in this brownfield redevelopment project involves the option to wait, option to abandon, option to switch, and so on.

\subsection{Applicability of Fuzzy Real Option in Brownfield Redevelopment Projects}

The parameters in the real option pricing model are fixed values, such as the present value of future cash flows and investment costs. However, the present value of future cash flows and investment costs in the brownfield redevelopment project can only estimate the general scope because of pollution factors. In view of this situation, these parameters are represented by fuzzy numbers. Thus, the fuzzy real option is a model which is very appropriate for the evaluation of brownfield redevelopment projects.

This paper describes the expected DCF value in a real option model by means of the normal fuzzy numbers, gets the volatility of the DCF value, combines with the B-S real option model, develops a fuzzy real option model, and finally applies the model to an industrial wasteland redevelopment project in Huainan City, China. There are two reasons for the usage of normal fuzzy numbers: one is that normal fuzzy numbers can reflect the fuzziness of the expected DCF value in brownfield redevelopment projects, and its cut-sets embody experts' risk preferences; the other one is that it is more suitable for assumed conditions of the Black-Scholes option [29].

\section{A Fuzzy Real Option Model}

\subsection{Basic Real Option Model}

Pricing methods for a real option is patterned after methods for the financial option. Making comparisons of parameters of real options and financial options can get a real option pricing model. The B-S option model is the most commonly used pricing model currently:

$$
C=V N\left(d_{1}\right)-X e^{-r T} N\left(d_{2}\right) .
$$

where, $d_{1}=\frac{\ln (V / X)+\left(r+\frac{\sigma^{2}}{2}\right)}{\sigma \sqrt{T}}, d_{2}=d_{1}-\sigma \sqrt{T}, C$ represent the values of project choice ROV (Real Options Value) $V$ represents the expected DCF value, $X$ represents expected investments or the cost of the project, $T$ represents the maximum deferred time, $r$ represents the risk-free interest, $\sigma$ represents the volatility of the expected DCF value, and $N(*)$ is a probability distribution function with standard normal distribution.

When applying B-S real option pricing models to mining brownfield redevelopment projects, we often find that it is difficult to evaluate the expected DCF value $V$ and its volatility $\sigma$. This paper describes the expected DCF value $V$ by means of normal fuzzy numbers and evaluates its volatility $\sigma$.

\subsection{Valuation of the Expected DCF Value}

\subsubsection{Fuzzy Process of Experts' Opinions}

First of all, an expert panel provides analysis on a project and each expert gives an estimation interval for the expected value of DCF independently: 


$$
V^{K}=\left[V^{K_{1}}, V^{K_{2}}\right], k=1,2, \ldots, n,
$$

where $V^{K}$ is regarded as a $\alpha$ level set of a certain normal fuzzy number. Herein, the value range of $\alpha$ is $(0,1]$. If conservative experts are more prudent about the valuation, then the value of $\alpha$ will be relatively large, and generally larger than 0.5 . On the contrary, aggressive experts are more optimistic about the expected value, so the value of $\alpha$ will be relatively small, and generally smaller than 0.5 . In this way, the value of $\alpha$ can reflects the experts' risk preferences.

Next, subordinating degree functions within each expert's valuation intervals are found according to the $\alpha$ level cut-set formula for normal fuzzy numbers:

$$
\mu_{V^{k}}=e^{-\left|\frac{x-\alpha_{k}}{\sigma_{k}}\right|}, k=1,2, \ldots, n
$$

Hence, normal fuzzy numbers can be gotten after fuzzification of each expert's valuation intervals.

$$
\begin{gathered}
V^{k}=\left[V^{k_{1}}, V^{k_{2}}\right]=\left[a_{k}-\sigma_{k} \sqrt{-\ln \alpha}, \mathrm{a}_{k}+\sigma_{k} \sqrt{-\ln \alpha}\right], \\
a_{k}=\frac{V_{1}^{k_{1}}+V_{2}^{k_{2}}}{2}, \sigma_{k}=\frac{V_{2}^{k_{2}}-V_{1}^{k_{1}}}{2 \sqrt{\ln \alpha}}, k=1,2, \ldots, n .
\end{gathered}
$$

\subsubsection{Weight Determination for Experts' Opinions}

In order to minimize the negative influences from individuality deviation of experts, each expert's opinion should be weighted appropriately in the first place. The basic principle is that estimation intervals recognized by most experts are given higher weight. Firstly, the closeness degree of normal fuzzy sets given by two experts is figured out in accordance with the closeness degree formula for fuzzy numbers. If estimation intervals given by the expert $i$ and the expert $j$ are converted to two normal fuzzy numbers $\bar{V}^{i}$ and $\bar{V}^{j}$, then their subordinating degree is $\mu_{V^{i}}=e^{-\left|\frac{x-a_{i}}{\sigma_{i}}\right|}$ and $\mu_{V^{j}}=e^{-\left|\frac{x-a_{j}}{\sigma_{j}}\right|}$ respectively, and the closeness of their fuzzy sets can be shown in Figure 1.

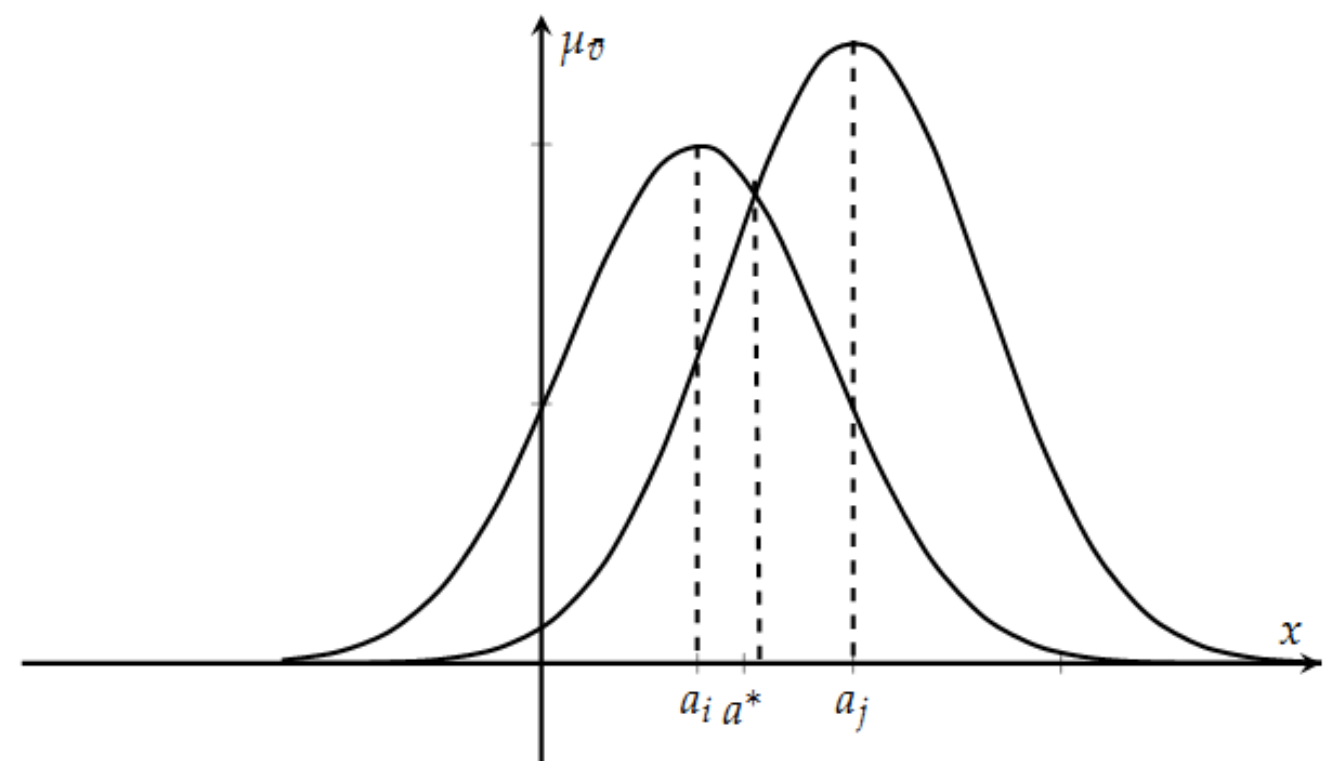

Figure 1. Schematic of the fuzzy closeness degree. 
Its corresponding computational formula is as follows:

$$
N_{L}\left(\bar{V}^{i}, \bar{V}^{j}\right)=\left(\bar{V}^{i} \oplus \bar{V}^{j}\right) \wedge\left(1-\bar{V}^{i} \oplus \bar{V}^{j}\right)=\bar{V}^{i} \oplus \bar{V}^{j}=e^{-\left|\frac{a_{j}-a_{i}{ }^{2}}{\sigma_{i}+\sigma_{j}}\right|^{2}}
$$

Then, a decision relation matrix is formulated on the basis of the results from pairwise comparisons of the closeness degree:

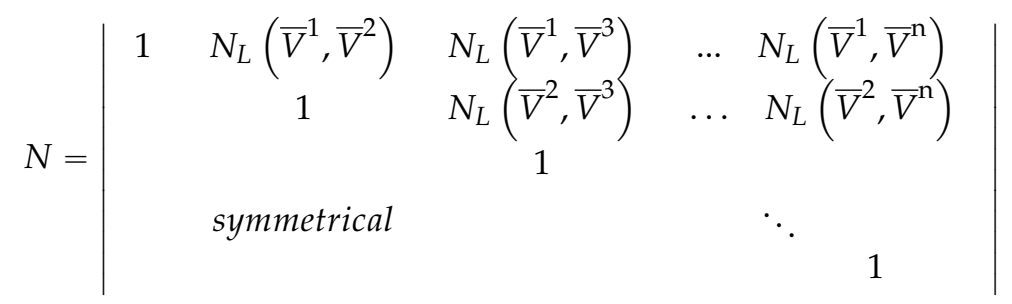

Given $N_{L}^{i}$ expresses the closeness degree of expert $i$ and other experts:

$$
N_{L}^{i}=\sum_{j=1, j \neq i}^{n} N_{L}\left(\bar{V}^{i}, \bar{V}^{j}\right), i=1,2, \ldots, \mathrm{K}
$$

The smaller the value of $N_{L}^{i}$, the fewer differences between the expert $i$ and other experts are. Thus, experts' weights can be gotten from the following formula:

$$
W_{i}=\frac{N_{L}^{i}}{\sum_{j=1}^{n} N_{L}^{j}}, i=1,2, \ldots, \mathrm{K}
$$

\subsubsection{Determination of the Expected Value of DCF}

In the previous parts, it is known how the estimation intervals given by experts have been fuzzed, and the results can be regarded as different $\alpha$ level cut-sets of normal fuzzy numbers.

$$
\bar{V}_{\alpha}^{k}=\left[\bar{V}_{1}^{k}, \bar{V}_{2}^{k}\right], k=1,2, \ldots, n .
$$

According to the weight of experts' opinions discussed in previous parts of this paper, multiple experts' opinions can be divided into different sets with various confidence coefficients $\alpha$, and the estimation interval of expected value of DCF $S$ will be obtained. In line with the extension principle of fuzzy sets, it can be found that $\bar{V}_{\alpha}$ is still an $\alpha$ level cut-set of fuzzy numbers.

$$
\begin{gathered}
\bar{V}_{\alpha}=\sum_{i=1}^{n} W_{k} \times \bar{V}_{\alpha}^{k} \\
\bar{V}_{\alpha}=\left[\sum_{k=1}^{n} W_{i} \times \bar{V}_{1}^{i}, \sum_{i=1}^{n} W_{i} \times \bar{V}_{2}^{i}\right]=\left[\bar{V}_{1}, \bar{V}_{2}\right]
\end{gathered}
$$

\subsection{Estimation of Volatility $\sigma$ of the Expected DCF Value}

Generally speaking, valuation for parameters volatility $\sigma$ in real option models are mainly rely on logarithmic income method, assets price fluctuation method, GARCH method, decision-making level approximation method, and so on. This paper adopts the assets price fluctuation method. It can be 
known from the previous parts that the expected DCF value is still a normal fuzzy number, and the corresponding subordinating function of its $\alpha$ level cut set $\bar{V}_{\alpha}$ is as follows:

$$
\mu_{\bar{V}_{\alpha}}=e^{-\left|\frac{x-a}{\sigma^{\prime}}\right| 2}, \text { where } a=\frac{\bar{V}_{1}+\bar{V}_{2}}{2}, \sigma^{\prime}=\frac{\bar{V}_{2}-\bar{V}_{1}}{2 \sqrt{-\ln \alpha}} .
$$

The volatility is obtained:

$$
\sigma=\frac{\sigma^{\prime}}{a}=\frac{\bar{V}_{2}-\bar{V}_{1}}{\left(\bar{V}_{1}+\bar{V}_{2}\right) \sqrt{-\ln \alpha}}
$$

\subsection{A Fuzzy Real Option Model in Consideration of Experts' Preferences}

Combing with the expected DCF value $V$, its volatility $\sigma$, and the previously mentioned real option pricing model from Equation (1), we can get a fuzzy real option model based on normal fuzzy numbers as follows:

$$
\widetilde{C}=\bar{V} N\left(d_{1}\right)-X e^{-r T} N\left(d_{2}\right) .
$$

Wherein, $d_{1}=\frac{\ln (a / X)+\left(r+\frac{\sigma^{2}}{2}\right) T}{\sigma \sqrt{T}} ; d_{2}=d_{1}-\sigma \sqrt{T}$.

The real option value gotten is still an $\alpha$ level cut-set of normal fuzzy numbers. In accordance with Equation (12), its expected value can be obtained as follows:

$$
E(\widetilde{C})=\frac{\widetilde{C}_{1}+\widetilde{C}_{2}}{2}
$$

\section{Case Study Results and Analysis}

\subsection{Case Introduction}

The case is a subproject of a redevelopment project for a mining subsidence area in a mining industrial city. The area, covering an area of 40 square hectometers, was an abandoned land of a small-scale coal mine. This moderately-polluted area is five kilometers away from downtown, and has few geographic advantages. The risk-free interest $r$ is designated as $5 \%$. After argumentation of the expert panel, the initial investment of this project is expected as 432,000 Yuan (RMB). The expected DCF value was given by five members of the expert panel, and their estimation intervals are as follows (Table 1):

Table 1. Estimation intervals of expected DCF value by five experts.

\begin{tabular}{cccccc}
\hline $\boldsymbol{V}$ & Exert 1 & Expert 2 & Expert 3 & Expert 4 & Expert 5 \\
\hline$V_{1}^{k}$ & 376,000 & 355,000 & 400,000 & 368,000 & 400,000 \\
$V_{2}^{k}$ & 398,332 & 445,000 & 440,000 & 456,000 & 500,000 \\
\hline
\end{tabular}

\subsection{Identification of the Real Option in the Case}

Mining wasteland redevelopment projects differ from common land development projects owing to the fact that the mining wasteland redevelopment projects could be deferred, abandoned, changed before their pollution factors are eliminated completely, or the redevelopment has not met the national development criteria. Moreover, according to Decree No. 20 issued by Ministry of Land and Resources in June, 2012, the maximum term for land development is two years, which means the mining wasteland redevelopment projects have a two-year elimination period or waiting period. To sum up, the real option in this project involves an option to wait, option to abandon, option to switch, and so on. This paper only discusses an option to wait or waiting option for simplification. 


\subsection{Empirical Results}

First of all, estimation intervals given by the expert panel were regarded as an $\alpha$ level cut-set of a normal fuzzy number. For the sake of simple calculation, given that each expert's risk preference is neutral and $\alpha$ is $0.5, a_{k}$ and $\sigma_{k}$ of the subordinating function can be found by means of Equation (5) as follows (Table 2):

Table 2. Parameter values.

\begin{tabular}{cccccc}
\hline Parameter & Expert 1 & Expert 2 & Expert 3 & Expert 4 & Expert 5 \\
\hline$a_{k}$ & 387,166 & 400,000 & 420,000 & 412,000 & 450,000 \\
$\sigma_{k}$ & 13,412 & 54,051 & 24,022 & 52,849 & 60,056 \\
\hline
\end{tabular}

The closeness degree of fuzzy sets was found by means of Equation (6), in accordance with parameters $a_{k}$ and $\sigma_{k}(k=1,2, \ldots, \mathrm{n})$. For instance, $N_{L}\left(\bar{V}^{1}, \bar{V}^{2}\right)=N_{L}\left(\bar{V}^{2}, \bar{V}^{1}\right)=e^{-\left|\frac{a_{2}-a_{1}}{\sigma_{1}+\sigma_{2}}\right|^{2}}=$ 0.964457. On this basis, a strategy correlation matrix was constructed and the weight of experts' estimated information was determined in line with Equations (8) and (9).

$$
W_{1}=0.167551, W_{2}=0.223994, W_{3}=0.197200, W_{4}=0.225492, W_{5}=0.185763
$$

Given the confidence level $\alpha$ is 0.5 , through Equations (11) and (12), the fuzzy estimation intervals of the expected DCF value were found as follows:

$$
\bar{V}_{0.5}=\left[\sum_{k=1}^{5} W_{i} \times \bar{V}_{1}^{i}, \sum_{i=1}^{5} W_{i} \times \bar{V}_{2}^{i}\right]=\left[\bar{V}_{1}, \bar{V}_{2}\right]=[378683,448892]
$$

Two parameters of the subordinate function are $a=\frac{\bar{V}_{1}+\bar{V}_{2}}{2}=413788, \sigma^{\prime}=\frac{\bar{V}_{2}-\bar{V}_{1}}{2 \sqrt{-\ln \alpha}}=42165$ respectively. The volatility of the expected DCF value is obtained by Equation (14), $\sigma=\frac{\sigma^{\prime}}{a}=\frac{42165}{413788} \approx$ 0.1019 .

Given the risk-free interest $r$ is $5 \%$, maximum tardiness $T$ is two years, the estimation intervals of the waiting option are $\widetilde{C}=[10616,49549]$, and its expected value is $E(\tilde{C})=30078$.

\subsection{Results Analysis}

As the expected investment is 432,000 Yuan, and the expected DCF value is 413,788 Yuan, the net present value is $E(N P V)=-182120$, which means this project is infeasible and should be given up.

If the waiting option is considered, the investment value of this project is $V=E(N P V)+$ $E(\tilde{C})=11866$, which is far greater than 0 , then this project is feasible and should not be given up. Rather than implement the project immediately, it is better to execute its waiting option two years later. It can be read from the empirical results that the fuzzy real option method takes project management flexibility and uncertainty into consideration, which is helpful to accurately evaluate the investment value.

\section{Conclusions and Prospects}

Pollution factors make mining brownfield redevelopment projects full of risks and uncertainty. Such traditional value evaluation methods as the net present value method do not consider the project flexibility and uncertainty for mining brownfield redevelopment, which will underestimate the projects' investment value. This paper built a real option model based on normal fuzzy numbers. The empirical results show that the application of normal fuzzy numbers not only reflects fuzziness 
of the expected DCF value of mining brownfield redevelopment projects, but also considers experts' risk preferences, which makes valuation results more objective and accurate. An objective weighting approach based on the lattice closeness degree minimizes deviation of experts' individuality. The application of real options takes account of investment project's flexibility, which making the valuation results more accurate.

This paper only discusses the waiting option implying in mining brownfield redevelopment projects, filtering other options, such as option to contract or option to switch. Therefore, defining those options, their correlation, and their influences on mining brownfield redevelopment projects are subject to the further study.

Acknowledgments: This study was supported in part by: the Ministry of Education Foundation for Humanities and Social Science (No. 11YJA790133), the Jiangsu Province Foundation for Philosophy and Social Sciences (No. 12EYA001), the Bidding Project of the Research Center for Resource-based Cities' Development of Huainan Normal University (No. SK2014A099), the Program for Innovative Research Team in Huainan Normal University, the CNAC Foundation for Generalized Virtual Economics (No. GX2012-1023(Y)), Jiangsu Province Foundation for the Innovation Cultivation of graduate students (CXLX12_0178).

Author Contributions: All of the authors made contributions to the work in this paper. Tao Sun and Hongjun Dai designed the research. Hongjun Dai contributed to model development, data collection. Wen Guo analyzed the data. Tao Sun provided guidance for writing this paper. Hongjun Dai wrote the paper. All authors have read and approved the final manuscript. We would like to acknowledge the reviewers for the comments that enhanced the quality of the manuscript.

Conflicts of Interest: The authors declare no conflict of interest.

\section{References}

1. Song, M.; Wang, S.; Yu, H.; Yang, L.; Wu, J. To reduce energy consumption and to maintain rapid economic growth: Analysis of the condition in China based on expended IPAT model. Renew. Sustain. Energy Rev. 2011, 15, 5129-5134. [CrossRef]

2. Zhang, N.; Kong, F.; Choi, Y.; Zhou, P. The effect of size-control policy on unified energy and carbon efficiency for Chinese fossil fuel power plants. Energy Policy 2014, 70, 193-200. [CrossRef]

3. Choi, Y.; Zhang, N.; Zhou, P. Efficiency and abatement costs of energy-related $\mathrm{CO}_{2}$ emissions in China: A slacks-based efficiency measure. Appl. Energy 2012, 98, 198-208. [CrossRef]

4. Kivel, P. Land and the City: Patterns and Processes of Urban Change; Routledge: London, UK, 1993.

5. Niall, G.K. Production Site: The Thinking of Post-Industrial Landscape; E\&F SPonp Press: London, UK, 2001.

6. Rosalind, G.; Yesim, S.E. Recycling the City -The Use and Reuse of Urban and the Land; Lincoln Institute of Land Policy: Cambridge, MA, USA, 2004.

7. David, B.F. Brownfield Redevelopment Initiatives: Federal and Selected State Programs. Aliaba Course Study 2007, 10, 18-19.

8. Hugehes, A.; Mark, A. Dirt into Dollars: Converting Vacant Land Into Valuable Development. Available online: http://www.brookings.edu/research/articles/2000/06/summer-metropolitanpolicy-hughes (accessed on 3 February 2016).

9. Rutherford, H.P; Rowan, R. The Metropolitan Portland Urban Natural Resource Program in the Ecological City; University of Massachusetts Press: Amherst, MA, USA, 1994; pp. 251-267.

10. Cao, K.; Jin, T. A Discussion on Brownfield Redevelopment Strategies in Western Countries and Its Inspiration to China. China Popul. Resour. Environ. 2007, 17, 124-129.

11. Tang, Y.-T.; Nathanail, C.P. Sticks and Stones: The Impact of the Definitions of Brownfield in Policies on Socio-Economic Sustainability. Sustainability 2012, 4, 840-862. [CrossRef]

12. BenDor, T.K.; Metcalf, S.S.; Paich, M. The Dynamics of Brownfield Redevelopment. Sustainability 2011, 3, 914-936. [CrossRef]

13. Ridker, G.R.; Henning, J.A. The determinants of residential property values with special reference to air pollution. Rev. Econ. Stat. 1967, 49, 246-257. [CrossRef]

14. Rosen, S. Hedonic prices and implicit markets: Product differentiation in pure competition. J. Polit. Econ. 1974, 82, 34-55. [CrossRef] 
15. Anish, N.; Kent, G. Urban Property Values and Contaminated Sites: A Hedonic Analysis of Scdney, Nova Scotia. J. Environ. Manag. 2008, 88, 1212-1220.

16. Campanella, J. Valuing partial losses in contamination cases. Apprais. J. 1984, 52, 301-304.

17. Jackson, T.O. The Effects of Previous Environmental Contamination on Industrial Real Estate Prices. Apprais. J. 2001, 69, 200-210.

18. Kinnard, W.N.; Worzala, E.M. How North American appraisers value contaminated property and associated stigma. Apprais. J. 1999, 67, 269-279.

19. Mundy, B. The Impact of Hazardous Materials on Property Value. Available online: http:/ / onlineed.appraisalinstitute.org/ai/OnlineEd/Resources/ol667/bibliography/w18_ hazardousmaterials.pdf (accessed on 3 February 2016).

20. Patchin, P.J. Contaminated properties and the sales comparison approach. Apprais. J. 1994, 62, 402-409.

21. Jacilson, T.O. The effects of environmental contamination on real estate: A literature review. J. Real Estate Lit. 2001, 9, 93-116.

22. Richards, T. Valuing contaminated land and property: Theory and practice. J. Propert. Valuat. Invest. 1996, 14, 6-17. [CrossRef]

23. Syms, P.M. Contaminated Land: The Practice and Economics of Redevelopment; Blackwell Scince: London, UK, 1997; pp. 30-31.

24. Wang, Q.; Keith, W.H. Fuzzy real options in brownfield redevelopment evaluation. J. Appl. Math. Decis. Sci. 2009, 2009, 1-16. [CrossRef]

25. Wang, Q.; Keith, W.H. A numerical method of evaluation brownfields using fuzzy boundaries and fuzzy real options. Syst. Man Cybern. 2010. [CrossRef]

26. Wang, Q.; Kilgour, D.M. Fuzzy real options for risky project evaluation using least squares Monte-Carlo simulation. IEEE Syst. J. 2011, 5, 385-395. [CrossRef]

27. Ai, D.; Zhu, T.; Yue, X. Discussion on Valuing Contaminated Land. Ecol. Environ. Sci. 2010, 5, 1253-1260.

28. Zhang, L.; Li, Y.; Li, J. Summary and Review of Foreign Methods and Practice for Brownfield Valuation. China Popul. Res. Environ. 2012, 4, 131-136.

29. Yao, S. Fuzzy Real Option Valuation in a Brownfield Redevelopment Project. Master's Thesis, Hefei University of Technology, Hefei, China, 2013.

30. Fischer, B.; Myron, S. Scholes, The pricing of options and corporate liabilities. J. Polit. Econ. 1973, 81, 635-654.

31. Myers, S.C. Determinants of corporate borrowing. J. Financ. Econ. 1977, 5, 147-175. [CrossRef]

32. Carlssona, C.; Fullera, R. On Fuzzy Real Option Valuation. Available online: http://uni-obuda.hu/users / fuller.robert/TR367.pdf (accessed on 3 Ferurary 2016).

33. Carlssona, C.; Fullera, R. A fuzzy approach to real option valuation. Fuzzy Set. Syst. 2003, 139, $297-312$. [CrossRef]

34. Wang, J.; Hwang, W.L. A fuzzy set approach for R\&D portfolio selection using a real options valuation model. Omega 2007, 35, 247-257.

35. Lee, C.; Tzeng, G.; Wang, S. A fuzzy set approach for generalized crr model: An empirical analysis of S\&P 500 index options. Rev. Quant. Financ. Account. 2005, 25, 255-275.

(C) 2016 by the authors; licensee MDPI, Basel, Switzerland. This article is an open access article distributed under the terms and conditions of the Creative Commons by Attribution (CC-BY) license (http://creativecommons.org/licenses/by/4.0/). 